\title{
LUCIIOLA, DE JOSÉ DE ALENCAR, ROMANCE FISIOLÓGICO: INTERSECÇÕES ENTRE LITERATURA E MEDICINA
}

Gabriel Queiroz Guimarães Hernandes Doutorando em Teoria Literária e Literatura Comparada pela Universidade de São Paulo

Bolsista CAPES

gabriel.hernandes@usp.br

\section{RESUMO}

O presente artigo visa estudar algumas interseções entre a literatura e a medicina no século XIX por meio do romance Lucíola, de José de Alencar. A partir da classificação de "romance fisiológico", feita pelo próprio autor, objetiva-se examinar como essa denominação está articulada às concepções médicas do período e como estas se associam à estrutura geral do livro estudado. Por fim, a análise se pautará na relação entre a imagem feminina presente nos perfis do autor com a noção de patologia dos manuais médicos e seu significado social e cultural.

Palavras-chave: romantismo, corpo, medicina, romance, século XIX.

\section{ABSTRACT}

This article studies some relations between Literature and Medical Discourse in the $19^{\text {th }}$ century in Luciola, a novel from the Romantic period written by José de Alencar. At the time, Alencar classified this specific narrative as a "physiologic novel". Hence, taking the author's classification into consideration, we try to understand how the novel is related to the medical conceptions of its time and how these conceptions can be associated with the general structure of the book. Finally, the analysis focuses on the articulation between the feminine perspective of the author and the notion of pathology in the medical books and their social and cultural significance.

Keywords: romanticism, body, medicine, novel, 19th century. 


\section{Corpo e história: situando o problema}

Em um de seus livros dedicados a estudar o corpo, Jean-Jacques Courtine, percuciente estudioso das obras de Foucault, afirma que "é, em grande parte à obra foucaultiana que se deve o enraizamento inicial do corpo no discurso das ciências humanas" (COURTINE, 2013, p. 17). No pensamento do autor de As palavras e as coisas, ainda segundo o estudioso mencionado, o corpo é palco de disputas discursivas as quais produzem diferentes feixes relacionais de poder, nos quais subsistem técnicas milenares, além de dispositivos de vigilância e dominação, em que os próprios indivíduos "chegam a exercer sobre seu próprio corpo 'técnicas de sua natureza', no uso dos prazeres e das paixões" (COURTINE, 2013, p. 17).

Dentre os inúmeros feixes de relações de poder que são incididos sobre os corpos, a medicina exerce um papel considerável na atribuição de sentidos que são neles impressos, ao contribuir para a maneira de se relacionar com nosso próprio organismo e alterando hábitos movidos pela necessidade do cuidado pessoal. Os exemplos cotidianos são inúmeros, mas, a fim de mera exemplificação, cabe mencionar o uso de protetores solares para prevenir o câncer de pele, o consumo (ou não) de produtos orgânicos para evitar o consumo de agrotóxicos, a diminuição de sal nas refeições para pessoas hipertensas etc. Como se pode notar, a incidência desse poder pode estar relacionada a conflitos entre poderes diversos. Um exemplo disso é o intrincado conflito econômico por trás do uso (ou não) de agrotóxicos na produção agrícola, cujos interesses envolvem latifundiários e praticantes da agricultura familiar.

No Brasil do século XIX, as relações entre o corpo e o poder estavam imersas em outra estrutura social, cultural e econômica. Apesar da simplicidade da afirmação, as 
consequências dessa diferença acarretam em modos diferentes de ler/analisar a imbricação dos diferentes discursos e práticas do corpo na história e, desse modo, compreender especificidades de certos modelos de poder em uma sociedade distanciada da nossa pelo tempo. Ao relacionar esse corpo com a literatura, contudo, adentramos em um caminho ainda mais tortuoso, pois, como esclarece Antonio Candido,

o primeiro passo (que apesar de óbvio deve ser assinalado) [ao realizar um estudo sociológico da literatura] é ter consciência da relação arbitrária e deformante que o trabalho artístico estabelece com a realidade, mesmo quando pretende observá-la e transpô-la rigorosamente, pois a mimese é sempre uma forma de poiese (CANDIDO, 2011, p. 22).

Alinhado ao apontamento do autor de A formação da literatura brasileira, a sondagem por interseções entre a literatura e medicina deve se ater às especificidades das duas áreas. Se, por um lado, no fazer literário, o escritor se sente livre para "desrespeitar" dados da ciência para desígnios estruturais e formais da obra; a medicina, por sua vez, forja determinado olhar para a realidade e, desse modo, produz por meio de seus enunciados definições para conceitos como "corpo" e "doença".

A fim de aproximar essas duas áreas tão distintas, o presente artigo empreende, em forma de ensaio, sondagens em textos e ideias que circularam no período de modo a tentar compreender as diferentes discussões envolvendo o corpo humano que permearam os dois tipos de produções. Como modo de aproximação, o nosso foco está voltado à estrutura geral do romance Lucíola na tentativa de compreender a denominação, dada por Alencar, de "romance fisiológico". Desse modo, estudaremos os 
manuais médicos, especialmente aqueles dedicados à fisiologia, como modo de tentar restituir a expressão para seu tempo histórico.

A hipótese que orienta essa leitura é a de que, por meio dessa denominação e pelas escolhas formais do escritor em sua obra, encontram-se respostas implícitas a debates da época acerca do corpo que estiveram presentes e em pauta nas diferentes ciências (filosofia, medicina, antropologia, sociologia e, claro, literatura). Acreditamos que em muitas passagens e, em especial na estrutura textual, os escritores literários inseriram-se em diversos debates sociais ao assumirem certas concepções que estão imersas em diferentes relações de poder, seja por meio de prescrições das condutas aceitáveis, na atribuição de modelos de normalidade, enfim, por meio de dispositivos discursivos variados.

\section{O perfil feminino e o corpo}

José de Alencar foi um escritor que se envolveu em uma série de polêmicas ao longo de sua vida. A afirmação pode ser comprovada pela observação do início de sua carreira literária que ganhou notoriedade, efetivamente, a partir das críticas que teceu à epopeia Confederação dos Tamoios, de Gonçalves de Magalhães, o visconde do Araguaia. A partir dessa discussão, lançaria a primeira obra que se destacaria no cenário indianista nacional com $O$ Guarani e, posteriormente a esse lançamento, ganharia maior destaque com a prosa poética de Iracema, livro que seria amplamente elogiado na época, inclusive, pelo Machado de Assis crítico.

Apesar do notório sucesso obtido com os romances indianistas, José de Alencar, contudo, iniciou sua carreira literária com dois romances urbanos, cujos conflitos centrais 
gravitam em torno de questões referentes ao casamento no século XIX: Cinco minutos (1856) e A viuvinha (1857). No entanto, a despeito de sua numerosa fiç̧ão citadina, os romances de maior destaque do escritor cearense são aqueles em que traça os seus "perfis de mulher": Lucíola (1862), Diva (1864) e Senhora (1875). Além desses, integram ao seu rol de enredos da cidade as narrativas: A pata da gazela (1870), Sonhos d'ouro (1872) e Encarnação (publicado postumamente em livro no ano de 1893).

De toda a sua extensa narrativa urbana, contudo, o presente artigo sondará as relações entre o corpo no discurso médico e literário de José de Alencar somente em seu primeiro perfil de mulher e, além dele, teceremos algumas breves considerações que acabam sendo pertinentes nos demais. O romance Lucíola trata do caso de amor entre uma cortesã e o narrador da história, Paulo. Os dois se conhecem em uma festa popular e, embasado por um engano ao olhar para a moça, o rapaz a trata de forma cortês, sendo logo repreendido por seu amigo que indica a profissão da moça.

O enredo todo é o desenvolvimento desse engano inicial, visto que, nesse primeiro momento, Lúcia mostra-se ao narrador repleta de signos de pureza e, ao longo da narrativa, as duas faces da cortesã, aquela "pura" que seria referente a seu verdadeiro caráter e a outra, social, marcada pela prostituição. No desenrolar da trama, no momento em que a moça rememora seu passado e revela a necessidade que a levou à profissão, o narrador atesta a pureza de sua alma e ambos se mudam da cidade para o campo. Ao final, quando Lúcia, já morando afastada da cidade em um arrabalde, descobre-se grávida, um aborto espontâneo faz com que ela e o filho não resistam. Decorridos seis anos do episódio, Paulo rememora junto a G.M., sua interlocutora ao longo do livro, o seu infortúnio. 
Apesar de uma narrativa que enfoca tantos aspectos, como o interesse sociológico presente na profissão de Lúcia; aspectos que interessam à área da psicologia pela análise tecida pelo narrador sobre as excentricidades da moça; aspectos históricos que estão presentes nos costumes, como a festa da Glória, por ele registrada; dentre outros que dizem respeito a diversas áreas de interesse das ciências humanas, Alencar denomina seu romance de fisiológico. Na polêmica que trava com Nabuco, por exemplo, o escritor menciona que em Lucíola há uma "tese fisiológica" (ALENCAR, 1978, p. 150).

Ao debater sobre Senhora, com D. Paula de Almeida, o seu autor, sob o pseudônimo de Elisa do Vale, é mais preciso ao definir toda a produção de seus perfis de mulher como "romance[s] fisiológico[s]" (ALENCAR, 1959c, p. 1212). Cabe mencionar que o termo "fisiologia", no século XIX, possuía uma concepção diferente daquela que concebemos hoje e, por conta dessa diferença, alguns mal-entendidos com relação ao termo podem ocorrer. Conforme esclarece Cavalcanti Proença, em um de seus estudos dedicados a Alencar, a fisiologia causa "confusão com a psicologia da nossa linguagem atual” (PROENÇA, 1972, p. 74), pois “o autor considerava 'fisiológicos' os romances que analisavam temperamentos" (PROENÇA, 1972, p. 74).

De fato, ao ler atentamente a carta escrita pelo autor sob o pseudônimo de Elisa do Vale, nota-se que, na sequência, é esclarecido que o estudo desempenhado pelas narrativas dos perfis de mulher recai sobre a alma. Contudo, é necessário examinar alguns pontos a fim de compreender um pouco melhor a especificidade do termo "fisiológico" no contexto em questão. Apesar da proximidade entre "psicológico" e "fisiológico", mencionada por Proença, não se trata de, simplesmente, substituir um termo pelo outro, mas, em sua especificidade, compreender algumas nuances que subjazem o uso do termo nesse determinado enunciado. 
Ao realizar a pesquisa no célebre dicionário de Morais, considerado por Alencar (1974) como “o primeiro lexicólogo da língua" (idem, p. 162) portuguesa do Brasil, o verbete não esclarece essa especificidade, visto que o termo "physiologia" é definido como "parte da Medicina, que ensina a conhecer a natureza do corpo humano" (SILVA, 1789, p.198). Curiosamente, o dicionário anterior que embasou o de Morais nos revela uma definição um pouco mais antiquada, porém mais próxima à definição apresentada por Proença, já que define o vocábulo do seguinte modo:

Deriva-se do Grego Physis, Natureza, \& Logos, Discurso, \& toma-se geralmente por Physica. Mas propriamente fallando, Physiologia he a parte da Medicina, q observa, \& considera a natureza do homem, a formação, conformação, \& perfeyção do feto, a differença dos temperamentos, \& das idades, os espíritos, as faculdades, os humores, \&c. \& tudo isto em ordem à cura de todo o gênero de doenças (BLUTEAU, 1720, p. 489).

Cabe destacar que a definição de Bluteau se pauta menos pela influência de uma medicina que estava se especializando, e mais na tradição clássica de viés holístico que orientava a prática médica no ocidente europeu da época. Nessa perspectiva, o corpo é regulado por uma série de humores (fleuma, bile negra, bile amarela e sangue) que determinavam os diferentes estados de saúde e doença, tal qual fora teorizado por Hipócrates e, além disso, associava-se à teoria da tradição galênica, cuja predominância de determinado humor acarretava em diferentes temperamentos: melancólico, fleumático, colérico e sanguíneo.

Ao longo do século XIX, contudo, a teoria humoral foi sendo suplantada por uma fisiologia cada vez mais pautada nas funções e sistemas dos órgãos, e a medicina, por sua vez, seria cada vez mais fragmentada em diferentes especializações. Contudo, cabe 
destacar que a passagem para a concepção do corpo enquanto "conjunto de órgãos-sede de processos fisiológicos e bioquímicos" (FAURE, 2009, p. 13) não esteve isenta de embates com a perspectiva humoral, amplamente presente na cultura popular do século em questão (cf. FAURE, 2009), e também que, entre os médicos, houve intenso conflito entre perspectivas "materialistas e espiritualistas, mecanicistas e vitalistas" (FAURE, 2009, p. 43).

Nesses debates presentes na época, Alencar parece inclinar-se para a perspectiva espiritualista, conforme é possível notar pela defesa que realiza dessa corrente fisiológica no romance Encarnação. Em uma discussão entre Henrique e a protagonista Amália, acerca dos delírios de outro personagem, o médico defende que as alucinações são frutos da crença no espírito e afirma que:

Só não as têm [as ilusões do espírito] os materialistas, aqueles para quem Deus é um absurdo, a pátria e a família uma comandita; gente que reduz a inteligência a um pouco de fósforo, e a virtude a uma convenção. Esses vivem fisicamente; são corpos que se transformam. Nós, porém, que nos remontamos à nossa origem divina, todos temos nossas abusões (ALENCAR, 1959a, p. 1243).

Para o espiritualista, a compreensão da natureza corporal não está destituída de uma estreita ligação com a natureza do próprio espírito, visto que corpo e alma estão indissociavelmente ligados. O visconde de Araguaia, em seu papel de médico inclinado ao espiritualismo, e que escreveu, além da epopeia Confederação dos Tamoios, tratados de filosofia e medicina, afirma em seu manual sobre frenologia que:

Podemos admittir que sirva o cérebro ao espirito como o piano ao artista que n'elle executa a musica que tem na mente, e póde variar o toque e as harmonias, sem 
poder exceder a capacidade sonora do seu instrumento, que assim limita a idéa e o sentimento do artista (MAGALHÃES, 1876, p. 27).

Nos manuais fisiológicos dos espiritualistas, em geral, a alma é um elemento que é levado em conta nas análises corporais e não somente os processos bioquímicos, os quais, na realidade, muitas vezes são relegados a um segundo plano. A explicação sobre o objeto de estudo da fisiologia em Moraes, por exemplo, é permeada por um devaneio, no qual ele conclui que

Sendo assim, é de razão que o Medico, defensor da honra da sua profissão, e zeloso do bem estar de seus doentes, cultive cuidadosamente o estudo da Anatomia do Espirito, bem como a do corpo; pois que ella está tão annexa á Natureza racional e methaphysica do homem e de todas as suas acções moraes, que ajunta a investigação, o saber outr'ora mais recommendado pelos nossos maiores: nosce te ipsum (MORAES, 1854, p. 20, grifos nossos).

Nesse sentido, a definição "romance fisiológico" possivelmente estava associada ao estudo de uma "alma", visto que, na mentalidade espiritualista, da qual Alencar parece partilhar os preceitos, o estudo do espírito não é destituído de interesse para esses fisiologistas. Não se trata precisamente de estudar um temperamento stricto sensu, visto que não se trata de enquadrar as personagens nas classificações clássicas de Galeno, mas de compreender as especificidades psicológicas e sociais de determinadas personagens.

O estudo do princípio espiritual para Alencar, contudo, parece não se tratar somente de focar na relação corpo e alma, e sim dimensionar as contradições entre a sociedade e o caráter das personagens. Na polêmica travada com Nabuco acerca de seus 
romances, o escritor estudado rebate a suposta falta de coesão em Lucíola nos seguintes termos:

Se o Sr. Nabuco está disposto a estudar, eu lhe mostrarei que essa dualidade é um fenômeno fisiológico muito comum, e reproduz-se frequentemente entre o homem e o indivíduo, entre a alma psicológica e a alma social, entre as aspirações e os fatos.

O poeta jungido à profissão material, pela necessidade de ganhar o pão; um rei fazendo violência a sua índole modesta e humilde, para governar; o criminoso, lutando como João Valjean, para reabilitar-se, mas sucumbindo acabrunhado pelo desprezo: isso que é senão o antagonismo da consciência com a vida, da alma com a sociedade? Quando Otelo beija Desdêmona adormecida e diz-Ihe: "Sê assim depois de morta: e eu te matarei e te amarei depois. Ainda um beijo, o último"; há aqui uma dualidade do coração, que no mesmo instante odeia e ama, que, à uma (sic), inebriase de volúpia e de sangue (ALENCAR, 1978, p. 152).

De fato, o romance Lucíola parece centrar-se nessa disputa entre uma alma "pura" e um corpo "corrompido" pela prostituição. Na interpretação em termos fisiológicos do romance, a contradição e a dualidade de Lúcia não permitiriam a "regeneração" da mulher "porque nas mais ardentes efusões desse amor achará a lembrança inexorável de seu erro" (ALENCAR, 1978, p. 150). Nesse viés é que Alencar define as suas heroínas dos perfis como "idiossincrasias morais" (ALENCAR, 1978, p. 150), pois seriam excentricidades produzidas pela sociedade artificial cujos valores são ditados pelo capital.

Ao considerarmos essa leitura, o romance Lucíola apresentaria esse embate entre a natureza espiritual de Lúcia, que seria de pureza, e o corpo corrompido socialmente por sua profissão. O embate entre natureza e sociedade transparece, especialmente, nos momentos em que o narrador a observa e, em lugar de notar uma mulher impudica, os indícios fisionômicos transmitem sinais castos. Como é possível perceber no momento em 
que o personagem Paulo a vê contemplando a lua na festa da Glória, cena que abre o romance, e nota que "ressumbrava na sua muda contemplação doce melancolia e não sei que laivos de tão ingênua castidade [...]" (ALENCAR, 1959a, p. 313).

O decorrer da narrativa evidencia que essa primeira observação é acertada, pois Lúcia revela-se, de fato, uma cortesã que mantém algo da "pureza" de sua alma. Além disso, o olhar percuciente de Paulo é capaz de sondar além da superfície social e notar o espírito da moça. Esse olhar que vai além da mera exterioridade corporal é outro dado que se associa à fisiologia da época, visto que houve certa recorrência da fisiognomia e da frenologia, disciplinas que intentavam compreender, pelo aspecto facial e pelo formato do crânio, algo sobre o caráter da pessoa, em discursos diversos da época. Na definição de Lavater, a maior referência da época sobre o assunto,

A fisiognomia é a ciência de conhecer o caráter (não os destinos aleatórios) de um ser humano lato sensu a partir de seus traços exteriores; a fisionomia lato sensu seriam portanto todos os traços exteriores do corpo e dos movimentos de um ser humano, na medida em que, a partir daí, é possível conhecer algo de seu caráter (LAVATER apud BOLLE, 1994, p. 41).

Grande parte do conflito de Lucíola decorre dessa tensão entre o caráter da protagonista e o papel desempenhado socialmente por ela. De acordo com a leitura que Alencar fornece de sua própria obra, contudo, essa oposição não estaria bem resolvida, pois por serem idiossincrasias morais o interessante ao estudar Lúcia, Emília e Aurélia seria precisamente "pela originalidade e aberração do viver comum" (ALENCAR, 1978, p. 150). 
No campo médico, contudo, essa "originalidade" e "aberração" não são consideradas um evento dotado de significância positiva, mas recaem sobre a patologia ao se afastarem daquilo que seria considerado a "normalidade" natural. Não era possível concretizar o "destino final" da mulher, pois os manuais médicos criavam

[...] uma imagem moralmente superior da mulher se o seu corpo cumprisse as funções sociais do casamento, da maternidade e da educação dos filhos, mas se a mulher não controlasse seus desejos e se entregasse ao mundanismo e ao desregramento, facilmente ultrapassaria a tênue fronteira entre a normalidade e a patologia, como tão incansavelmente os médicos vão alertar ao abordar temas como masturbação e prostituição (MARTINS, 2004, p. 41).

Os perfis femininos de Alencar deixam claro que há um desvio com relação à natureza, já que as protagonistas são todas apresentadas como moças independentes e fortes no princípio e, ao final dos romances, submetem-se aos homens. Na perspectiva do século, essa independência não era entendida positivamente, pois contrariava as leis do corpo, tal qual entendido pela medicina da época, e, desse modo, mostravam que essas mulheres "desejavam 'ser homens' e isto era contrário à Natureza [...]" (MARTINS, 2004, p. 14).

A conclusão dos conflitos dos perfis de Alencar parece sugerir precisamente que esse suposto desvio da natureza da mulher ou da alma das protagonistas teria sido resolvido. No romance Diva, Emília submete-se, mesmo que pela violência, a Amaral de quem se torna esposa. Em Senhora, após restituir à mulher o dinheiro e quitar sua dívida, Aurélia se submete a Fernando que assume o seu papel de homem. Lucíola, por sua vez, possui uma mensagem menos esperançosa, pois, apesar do abandono de Lúcia à prostituição, a tese fisiológica dessa narrativa indica que não haveria salvação para a 
cortesã, devido à nódoa que estaria impressa em seu corpo. Tanto que a moça não pode concretizar o grande ideal feminino, sintetizado nas palavras de Moraes ao dizer que as mulheres "foram criadas para ser esposas e mães" (MORAES, 1854, p. 28), pois não pode se casar com Paulo e morre no momento em que se descobre grávida.

\section{O papel social da mulher e a sua natureza médica}

No século XVIII e XIX, o gênero romance foi utilizado com propósitos moralizantes e fins didáticos. Na ficção de Alencar, os personagens apresentam condutas que não visam representar as coisas como elas são, mas como idealmente deveriam ser. Por representar modelos sociais almejados, as descrições das personagens evidenciam diferentes mecanismos de poder que estão relacionadas ao modo como, na época, diferentes papéis da sociedade eram concebidos, como, por exemplo, o feminino.

Ao relacionar a medicina da época com a literatura, procuramos por intersecções entre as duas áreas a fim de sondar a denominação de "romance fisiológico" e apontar, brevemente, alguns de seus desdobramentos na estrutura geral de Lucíola. Como pretendemos demonstrar, ainda que superficialmente, a classificação da narrativa em termos de "fisiologia" e os pressupostos que embasam esse tipo de rótulo não estão isentos de sua relevância histórica e revestem-se de significados que se articulam a diferentes poderes que vigoraram na época.

No caso do romance Lucíola, a articulação presente na denominação "romance fisiológico" conduz ao caráter misógino que rondava os discursos da época, que visavam atribuir como parâmetro de normalidade certo ideal feminino pautado na figura exemplar da mãe e dona de casa. Na contramão da postura idealizada, as coerções sociais da época 
reforçavam, como no caso da morte de Lúcia, que o papel contrário àquele almejado beirava a patologia e, como tal, deveria ser rechaçado. Nesse sentido, ao nomear suas personagens dos perfis femininos de "idiossincrasias morais", Alencar as estaria vinculando ao campo do patológico e, portanto, daquilo que precisaria ser sanado. O fim das tramas parece reforçar essa recondução às ideologias seculares do século XIX, visto que Lúcia morre por não poder constituir família; Emília, enfim, se submete a seu esposo; e Aurélia, ao perceber que Seixas se configurou enquanto um sujeito e não objeto ao quitar sua dívida com ela, também se submete e se torna uma dona de casa.

Desse modo, nota-se, pela estrutura geral desses romances, que a intenção deles era de orientar a postura feminina para determinada conduta socialmente aceitável. A justificativa para essa postura é dada, também, pela medicina, no entanto em termos de uma naturalização da submissão feminina pela análise fisiológica. Nesse sentido, o papel da mulher e do homem é concebido não em termos de convenções sociais, mas ditados pela própria natureza e, desse modo, romper com eles seria incorrer na deturpação do natural, o que reforçaria os paradigmas patriarcais tanto por meio da medicina como da literatura.

\section{Referências}

ALENCAR, José de. O nosso cancioneiro. In: COUTINHO, Afrânio. Caminhos do pensamento crítico. Vol. I. Rio de Janeiro: Ed. Americana, Prolivro, 1974. Encarnação. In: Obra completa. Vol. I. Rio de Janeiro: José Aguilar, 1959a.

Lucíola. In: . Obra completa. Vol. I. Rio de Janeiro: José Aguilar, 1959b. 
Senhora. In: . Obra completa. Vol. I. Rio de Janeiro: José Aguilar, 1959c.

Às quintas V. In: COUTINHO, Afrânio. A polêmica Alencar/Nabuco. Rio de Janeiro: Editora Universidade de Brasília, 1978.

BLUTEAU, Raphael. Vocabulario portuguez e latino. Vol. IV. Lisboa: Officina de Pascoal da Sylva, Impressor de Sua Magestade, 1720. Disponível em:

<https://digital.bbm.usp.br/handle/bbm/5442>. Acesso em: 25 jan. 2018.

BOLLE, Willi. Fisiognomia da metrópole moderna: representação da História em Walter Benjamin. São Paulo: Editora da Universidade de São Paulo, 1994.

CANDIDO, Antonio. Literatura e sociedade. 12 ed. Rio de Janeiro: Ouro sobre azul, 2011. COURTINE, Jean-Jacques. Decifrar o corpo: pensar com Foucault. Petrópolis, RJ: Vozes, 2013.

MAGALHÃES, Gonçalves de. A alma e o cérebro: estudos de psychologia e physiologia. Rio de Janeiro: Garnier, 1876. Disponível em: <https://www.bbm.usp.br>. Acesso em: 15 set. 2015.

MARTINS, Ana Paula Vosne. Visões do feminino: a medicina da mulher nos séculos XIX e XX. Rio de Janeiro: Editora Fiocruz, 2004.

MORAES, Alexandre José de Mello. Physiologia das paixões e affecções. Tomo I. Rio de Janeiro: Dois irmãos, 1854. Disponível em: <http://www.bbm.usp.br>. Acesso em: 09 set. 2015.

PROENÇA, Cavalcanti. José de Alencar na literatura brasileira. 2 ed. Rio de Janeiro: Civilização Brasileira, 1972.

SILVA, Antonio de Moraes. Diccionario da língua portugueza composto pelo padre $D$. Rafael Bluteau, reformado, e acrescentado por Antonio de Moraes Silva natural do Rio de Janeiro. Tomo II. Lisboa: Officina de Simão Thaddeo Ferreira, 1789. Disponível em: <https://digital.bbm.usp.br/handle/bbm/5413>. Acesso em: 25 jan. 2018.

Recebido em 16 de fevereiro de 2018. Aceito em 2 de março de 2018. 